Though open lifeboats offer, by rowing or sail, some form of propulsion and a chance of reaching land, they provide virtually no shelter. In Arctic storm conditions death from exposure to cold, wind, and sea spray would soon occur. Today open boats are being largely replaced by inflatable life-rafts. These can be conveniently stored on the upper deck for quick release and inflate themselves on entering the water. A convenient size holds 20 men, and is fitted with a canopy and entrances at both ends with curtains ; these can be laced up to give total protection or loosened as required for ventilation and observation. The enclosed space maintains warmth created by its occupants, who may remain dry, at rest, and, if necessary, huddled together for mutual warmth. The rafts are extremely stable and are usually accompanied by a pack of water and emergency rations for five days, seasickness pitts, and signalling devices. Once in the raft men are safe until they are picked up. They can expect to survive a further week or ten days after they have run out of water and many weeks without food. Though in a heavy sea even a brightly coloured raft may be difficult to spot, modern organizations for identification, search, and rescue should ensure survivors' being picked up well within this period.

In the circumstances of shipwreck the process of transferring from the sinking ship to raft or boat is invariably complicated by extreme conditions of weather, poor visibility or darkness, seasickness, and sometimes injury. Only good training, physical fitness, high morale, discipline, and a refusal to give up the struggle will ensure the maximum success. Only if this can be achieved will loss of life at sea be reduced to a minimum. Though good weather-forecasting may enable a ship to avoid a storm centre, it is always better in the long run to be fully prepared to deal with bad weather when it comes-often unexpectedly-than run away from it.

\section{Sniffly Schoolchildren}

About 100 different viruses have now been isolated from patients with upper respiratory disease, but we still have a very incomplete picture of their importance, particularly in respiratory disease of children. Though a number of studies have been made of children admitted to hospital or seen in clinics and of children seen by their general practitioner, they miss out the children who are not ill enough to cause concern to their parents and so continue at school, do not stay at home, and do not visit a doctor.

A first contribution towards filling this gap in knowledge has now been published by M. S. Pereira, B. E. Andrews, and S. D. Gardner. ${ }^{1}$ They studied a well-housed primary school in north-west London. They visited the school on alternate days for two years and persuaded any children whom they found who had colds to submit to a short examination, including nose and throat swab. It speaks well for their skill and the good relationships engendered that they achieved a steady rate of sampling throughout that time and isolated 59 viruses from 782 illnesses in 207 (about 75\%) of the children in the school. They were more successful in collecting specimens from the older children aged 10-11 years than from the younger aged 4-5 years. Nevertheless, viruses were isolated from about the same proportion of all age groups. These investigators obtained myxoviruses or similar organisms (that is, influenza, parainfluenza, or res- piratory syncytial virus) from 22 illnesses and rhinoviruses from 23. Eight of the remaining organisms were herpes simplex virus and two were Mycoplasma pneumoniae (also known as Eaton's agent, and not, strictly speaking, a virus at all). In 50 children from whom a virus was isolated there was nasal discharge, in 11 sore throat, and in 22 a cough. Four of six children infected with influenza A2 had only mild nasal symptoms, and five of seven children infected with respiratory syncytial virus lost no time from school. Nevertheless, 12 of the 59 illnesses in which a virus was isolated led to an absence from school, though usually this was only of one to three days.

The authors point out that, though waves of absence from school could be detected during epidemics of common infectious diseases such as measles, one in 10 of all children was away at other times at all seasons of the year. Since other studies have indicated that about $60 \%$ of the lost days were due to respiratory infection, ${ }^{2}$ these minor infections have an important aggregate effect, which could be estimated as an average of about one or two weeks of lost schooling per child per year-not to mention many other days of reduced attention and energy.

Unfortunately in spite of this and other careful studies we still cannot be sure that even the 100 viruses we know about are the cause of all this indisposition. Pereira and her colleagues found a virus or other pathogen in only $8 \%$ of their patients instead of the $30 \%$ achieved by similar techniques in a collaborative study in general practice and in hospital. ${ }^{3}$ In the latter study there was intrinsic evidence that these viruses often caused the illnesses in which they were isolated. Since the general pattern of virus isolation in the two studies was very similar, it might be argued that the different rates were found because there is a smaller chance of recovering viruses from mild illnesses than from severe ones. There was indeed some evidence within the collaborative study that those who saw milder illnesses recovered fewer viruses. On the other hand, some of these illnesses might be due to bacteria rather than viruses, but other workers have found little evidence of this. It is also likely that the isolation rate could be improved by using techniques such as organ cultures of human respiratory epithelium to pick up fastidious viruses.

If paired sera had been tested for antibodies some further infections would have been detected, but blood could not have been collected in this type of study without destroying co-operation, and in any case such mild infections do not regularly induce increasing antibody titres. Some of them may in fact be reinfections in which there is sufficient antibody in nasal secretions to prevent the shedding of virus even if illness occurs. There are few gaps in this investigation, but it would be very valuable to know whether the children from whom the simian virus type 5 (SV5) was apparently isolated developed antibodies against it. Moreover, unlike most workers, Pereira and colleagues recovered similar types of rhinoviruses repeatedly in the same population over two years. Is it possible that the results of serotyping were confused by the nonspecific neutralization shown by some animal sera? Or was there a rhinovirus carrier in the school ? The existence of such persons has been postulated, but so far they have never been detected.

\footnotetext{
' Pereira, M. S., Andrews, B. E., and Gardner, S. D., f. Hyg. (Lond.), $1967,65,475$

McDonald, J. C., Amer. Rev. resp. Dis., 1963, 88, 35

A report of the Medical Research Council Working Party, Brit. med. J.,
} 1965, 2, 319.

.

